\title{
Cassava Starch Edible Film Incorporated with Lemongrass Oil: Characteristics and Application
}

\author{
M. Dani Supardan ${ }^{1 *}$, Yulia Annisa ${ }^{2}$, Normalina Arpi ${ }^{2}$, Satriana $^{2,3}$, Wan Aida Wan Mustapha ${ }^{3}$ \\ ${ }^{1}$ Department of Chemical Engineering, Syiah Kuala University, Darussalam, Banda Aceh, 23111, Indonesia \\ E-mail: m.dani.supardan@che.unsyiah.ac.id \\ ${ }^{2}$ Department of Agriculture Product Technology, Syiah Kuala University, Darussalam, Banda Aceh, 23111, Indonesia \\ E-mail: yulia.ieca@gmail.com,normalina.arpi@unsyiah.ac.id \\ ${ }^{3}$ School of Chemical Sciences and Food Technology, Faculty of Science and Technology, Universiti Kebangsaan Malaysia, 43600 UKM, \\ Bangi, Selangor DE, Malaysia \\ E-mail: satriana@unsyiah.ac.id,wanaidawm@ukm.edu.my
}

\begin{abstract}
The objective of this research is to evaluate the effect of the addition of lemongrass essential oil (LGO) on the characteristics and antimicrobial properties of cassava starch based films. Edible films were prepared from a mixture of cassava starch and glycerol. LGO was added to edible films as natural antimicrobial agent. There was a reduction in tensile strength of edible film because of incorporation of LGO. The presence of LGO also caused to a reduction in roughness of the edible film. The experimental results showed that Trichoderma and Penicillium was not appear upon the film until the third day of incubation. Meanwhile, the use of edible films containing LGO as antimicrobial agents caused to a reduction in microbial counts of meat during storage.
\end{abstract}

Keywords - Cassava starch, edible film, essential oil, lemongrass

\section{INTRODUCTION}

Lemongrass (Cymbopogon citratus) is perennial herb largely cultivated in tropical and subtropical countries. The lemongrass essential oil (LGO) is widely used in perfumery industries and present biological activities as antibacterial, antifungal, anti-inflammatory and mosquito repellent. LGO mainly consists of citral. Citral is a racemic mixture of two monoterpene aldehydes; the geranial (cis-citral) and the neral (trans-citral). Previous studies showed that LGO had antimicrobial and antifungal activity against many strains such as Aspergillus flavus, Penicillium expansum, Aspergillus ochraceus, Fusarium moniliforme, Listeria monocytogenes, Staphylococcus aureus, Escherichia coli, Salmonella typhimurium [1-4]. Although, most of the essential oils such as LGO are classified as Generally Recognized as Safe (GRAS), its use as a food preservative often limited because of the flavor. Effective antimicrobial doses must not exceed consumers acceptable organoleptic levels [5]. To overcome this problem, one of the solutions is to incorporate essential oil into edible film.
Meanwhile, there is an increment of research devoted to the development of new biodegradable packaging materials, such as edible film. In food industry, Edible films can be utilized to meet challenges associated with long-term quality, market safety, nutritional value and economic production cost. Edible film defined as a thin layer, which can be consumed and wrapped on food [6]. These films may operate as carriers of many functional ingredients, such as antioxidants, antimicrobial agents, flavours, spices and colourants [7]. One of abundant agricultural commodity for edible film production is cassava. It is extensively cultivated as an annual crop in tropical and subtropical regions for its edible starchy tuberous root as major source of carbohydrates. This product has advantages in terms of transparency and resistance to oil and heat. However, the use of cassava starch is still constrained by its brittleness nature. The brittleness problem can be solved by the addition of glycerol [8].

In order to control undesirable microorganisms on food surfaces coated by edible film, volatile and non-volatile antimicrobial agents such as essential oil can be incorporated into edible film [9]. Essential oils represent an alternative to 
increase the water vapour barrier of edible films. The presence of essential oil in edible film have additional advantage, i.e. protection against microbial growth. In addition, incorporation edible film with essential oils could be used to slow down the oxidation process of lipid in various products with a high content in unsaturated fatty acids [10-11]. The use of edible films containing essential oil can inhibit the diffusion process of antimicrobial compounds into a product. It might be caused the essential oil forms part of the chemical structure of the film and interacts with the plasticizer and the polymer [12]. However, the incorporation of essential oil to the edible film was limited by the strong odour of essential oil and the possibilty of colour degradation of edible films.

The work reported in this paper was carried out to study the effect of the addition of LGO on the characteristics and antimicrobial properties of cassava starch-based films. The application of edible films for meat preservation was also investigated.

\section{EXPERIMENTAL PROCEDURE}

\section{A. Lemongrass Oil, Microbial and Cassava Starch}

Lemongrass was harvested from local farmer in Banda Aceh, Indonesia. LGO was extracted from stems and leaves of plant by conventional hydro-steam distillation apparatus for $4 \mathrm{~h}$. The oily layer obtained on top of the aqueous distillate was separated using funnel and dried over anhydrous sodium sulphate. The essential oil extracted was kept in sealed glass vials and covered with aluminium foil at ambient temperature until further analysis. Trichoderma (TC) and Penicillium (PC) was supplied from Bogor Agriculture Institute Culture Collection (Bogor, Indonesia). Both type of fungus was grown in Potato Dextrose Agar (PDA, oxoid) and kept at $4{ }^{\circ} \mathrm{C}$.

Cassava (Manihot esculenta) was purchased from local market in Banda Aceh, Indonesia. Tubers were peeled, washed, and chooped in small pieces. The chops were crumbled in blender machine, and then the starch slurry was filtered and left to sedimented in $48 \mathrm{~h}$. The sludge was took and oven-dried for $48 \mathrm{~h}$. Dried starch pulverized in a blender and sieved using 80 mesh sieve size. Starch was stored in plastic and kept in ambient temperature.

\section{B. Edible Films}

Cassava-starch film was prepared by dissolving a specific amount of cassava-starch into aqueous solution. The starch solution was stirred at $60{ }^{\circ} \mathrm{C}$ until it was completely dissolved. Afterwards, the viscous solution was left to cool in room temperature and then $3 \mathrm{~g}$ of glycerol was added as a plasticizer. Different portions of essential oils were slowly blended to the solutions. The mixture was casted onto $21 \mathrm{~cm}$ $\times 29 \mathrm{~cm}$ glass plates and left to dry under ambient laminar cabinet conditions for 3 days. The dried films were peeled and wrapped in alumunium foils and stored in a plastic clip until evaluation.

\section{Characterization and Antimicrobial Activity of Edible Film}

A universal test Machine (TA.XTplus model, Stable Micro Systems, Haslemere, England) was used to determine tensile strength. Four measurements were taken for the tensile tests. The surface of films was observed by Atomic Force Microscopy (AFM), using a Scanning Probe Microscope (Digital Instruments, Inc., Santa Barbara, California) with a $125 \times 125 \mu \mathrm{m}$ scan size and a $6 \mu \mathrm{m}$ vertical range. A three-dimensional image of a film surface area obtained in each test, and three images were obtained per formulation. A two-parameters related with sample roughness, i.e. average roughness, $\mathrm{Rq}$ (average of the absolute value of the height deviations from a mean surface), and root-mean-square roughness, $\mathrm{Ra}$ (root-meansquare average of height deviations taken from the mean data plane) were calculated.

Agar disc diffusion method with some modifications was used to assess the antimicrobial behavior of edible film. TC and $\mathrm{PC}$ culture was dissolved in a $\mathrm{NaCl}$ solution until reach a specific turbidity standard at a wavelength $530 \mathrm{~nm}$ (measured by spectrophotometer). The edible films from each variant were cut rectangular $(1.5 \mathrm{~cm} \times 1.5 \mathrm{~cm})$ and placed on Potato Dextrose Agar plates, which had been previously swapped with inoculums suspension. Edible films without essential oil content were also examined as reference. Then the plates were incubated at $37^{\circ} \mathrm{C}$. Observations of sample were made every day until microbial grows above edible film and the inhibition zones were created.

\section{Application of Edible Films}

Beef meat was obtained from a local supermarket in Banda Aceh, Indonesia. The meat was ground by using a mincer and was moulded in Petri dishes. The surface of both sides of the meat was coated with the films. The coating process was done under sterilized conditions using a laminar flow hood, thus, the initial microbiological population of the samples not to be modified. The coated samples were packed in polypropylene trays and stored without modified atmosphere at freezer. Evaluation of product was done at fourth days of the storage period. Meats without coating were also examined as reference.

\section{RESULTS AND DISCUSSIONS}

The content of LGO has an effect on the tensile strengths of edible film. Figure 1 shows that there was a reduction in tensile strength of edible film because of incorporation of LGO. The difference was explained by the loss of intermolecular interactions among starch molecules [13]. LGO may have caused some degree of rearrangement in the protein network, thus decreasing the film resistance to elongation. The experimental result show that the films with LGO were less resistant and less stretchable compared without LGO. It could be explained by the fact that lipids are unable to form a cohesive and continuous matrix [14]. Chen [15] stated that simple protein films are stronger and more stretchable than composite films containing lipids. In general, the mechanical behaviour of the film is greatly dependent on the kind of essential oil used. Lim et al. [16] has been reported that the physical properties of the film were not improved by the addition of thymol as active agent. It might be due to the addition of thymol increases the average pore size of films, resulting in decrease of tensile strength of film. Meanwhile, Pires et al. [17] also reported 
that the tensile strength did not significantly change when essential oils of coriander, tarragon and thyme, were added to Hake protein powder films.

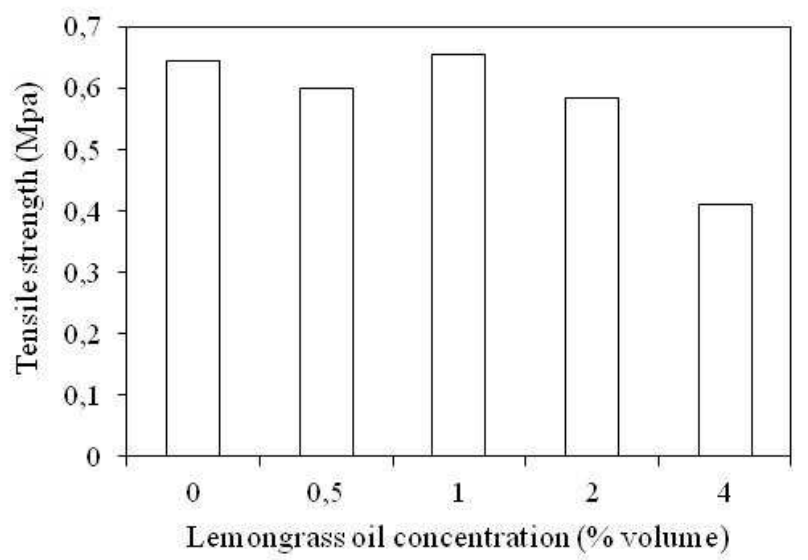

Fig. 1. Tensile strength as function of LGO concentration

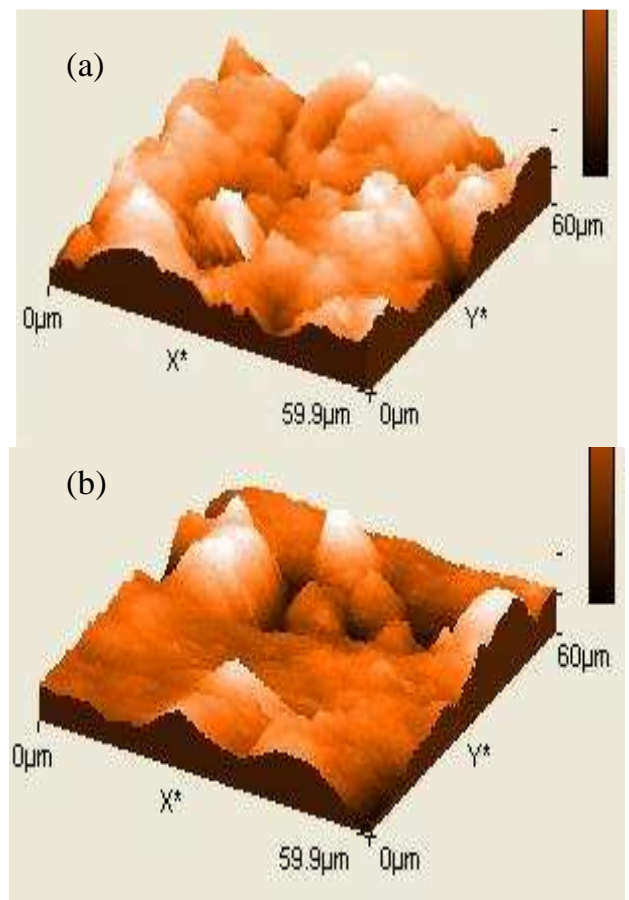

Fig. 2. Surface topographies of edible films; (a) wihout LGO; and (b) with LGO $1 \%$

In order to study the impact of LGO on the surface morphology of the films, AFM images were obtained. Figure 2 shows topographies of edible films. Meanwhile, Fig. 3 presents the results of roughness parameters $\mathrm{Ra}$ and $\mathrm{Rq}$ for formulated edible film. AFM images show that the film without LGO is rougher than the film with LGO $1 \%$. The presence of LGO caused to a reduction in roughness of the film, indicated by decreasing of $\mathrm{Ra}$ and $\mathrm{Rq}$ values. It might be due to the liquid state of the oils which extend over the protein matrix surface reducing its irregularities. Meanwhile, it was also observed that as the oil content increased in the formulation, an increase of $\mathrm{Ra}$ and $\mathrm{Rq}$ was observed (Fig. 3).
The roughness of the film surface tended to increase as LGO concentration increased. It may be linked to the greater progress of aggregation and creaming during the drying step, thus causing irregularities on the surface. The addition of ginger oil on soy protein isolate edible film showed a similar result trend [18]. Based on these results, a proper amount of LGO must be added to the film to make a film with a specific smooth surface.



Fig. 3. Roughness parameters of edible film as function of LGO concentration
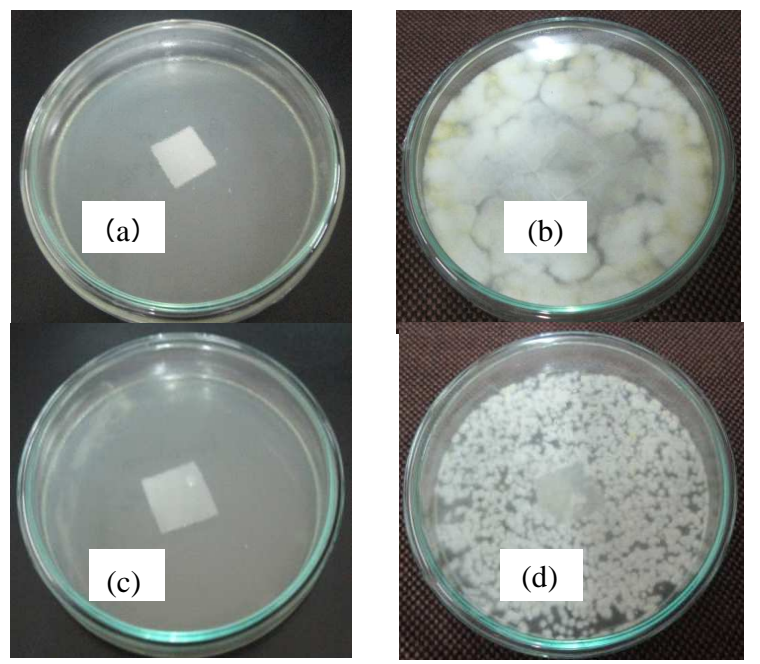

Fig. 4. Microbial growth : (a) TC on first day; (b) TC on fourth day; (c) PC on first day; (d) PC on fourth day

The antimicrobial properties of cassava starch-based films were presented in Fig. 4 and Table 1. Figure 4 shows the comparison of microbial growth on the first and fourth day of incubation. Meanwhile, Table 1 presents the experimental results of the antimicrobial activity of edible films containing LGO against TC and PC. It was observed that there is no microbial upon edible film until the third day for all of LGO concentration used. However, the microbial was sprout up upon the film on the fourth day. It was observed that there is no inhibition zones formed around the edible films on the fifth day. Similar results were observed for different concentration of LGO. The process of incubation at $37{ }^{\circ} \mathrm{C}$ can affect the active components composition in the LGO. Thus on the fourth day, the remnants of the active 
TABLE I

ANTIMICROBIAL EFFECT OF CASSAVA STARCH EDIBLE FILM INCORPORATED WITH DifFERENT LGO CONCENTRATIONS

\begin{tabular}{lcccccccccc}
\hline \multirow{2}{*}{ Films } & \multicolumn{3}{c}{ Day 1 } & \multicolumn{2}{c}{ Day 2 } & \multicolumn{2}{c}{ Day 3 } & \multicolumn{2}{c}{ Day 4 } & \multicolumn{2}{c}{ Day 5} \\
\cline { 2 - 11 } & TC & PC & TC & PC & TC & PC & TC & PC & TC & PC \\
\hline LGO 0 \% & - & - & - & - & - & - & + & - & + & + \\
LGO 0.5\% & - & - & - & - & - & - & + & + & + & + \\
LGO 1\% & - & - & - & - & - & - & + & + & + & + \\
LGO 2\% & - & - & - & - & - & - & - & + & + & + \\
LGO 3\% & - & - & - & - & - & - & + & - & + & + \\
LGO 4\% & - & - & - & - & - & - & + & - & + & + \\
\hline Note: TC : Trichoderma sp; PC : Penicillium sp & & & & & & \\
$\quad-\quad$ not grow upon edible film & & & & & & & \\
$\quad$ & : grow upon edible film
\end{tabular}

components in the edible film can no longer resist microbial attack. Release of antimicrobial in edible film depends on many factors such as electrostatic interactions between the antimicrobial agent and the polymer chains, osmosis, structural changes induced by the presence of antimicrobial, and environmental conditions [12].

Avila-Sosa et al [12] reported that chitosan and starch films retained volatile components present in the essential oil less effectively since it only has one type of polymer chain. Therefore, it allowed more volatile components into the vapor phase with resultant decrease in antimicrobial activities of the film. One of important antimicrobial component of the lemongrass is citra as an acyclic unsaturated monoterpene aldehyde compound [19]. Citral thought to inhibit microbial growth by damaging the cell membrane. This compound is known as volatile substance which is sensitive with thermal condition. Citral is found naturally in the volatile oils of citrus fruits, lemongrass, and other herbs and spices.

The film forming process may also influence the compounds of LGO. The production process suspected to make certain active compounds which effective against TC or PC are reduced or even vanished [20]. Effectiveness of antimicrobial agents is also affected by the amount or concentration of the substance. High concentrations of antimicrobial agents make microorganism harder to grown [20-21]. Allegedly the amount of LGO which were added in edible film is only enough to inhibit the growth of TC and PC until the fourth day. Liakos et al. [21] used higher concentration of LGO (16, 50 and $66 \%)$ in the film, the inhibition zone that performed was only about $0.5-3 \mathrm{~mm}$ (diameter) against E. coli. Furthermore, the LGO which incorporated to a matrix such as edible film is more difficult to migrate out so that the antimicrobial activity tends to be weaker than the activity of the oil directly.

The incorporation of LGO to edible film led to a reduction in the microbial counts of beef meat during storage in freezer. This reduction was more marked in terms of total microbial counts (Fig. 5). The microbial counts in coated meat with LGO was lower than samples uncoated and coated without LGO. Therefore, it can be concluded that the incorporation of LGO to edible film have been proved to be effective against microbial. The antimicrobial agents can serve as a carrier for antimicrobial compounds and/or antioxidants compounds in order to maintain high concentrations of preservatives on the food surfaces. The use of edible films containing antimicrobial agents could be an alternative to extend meat shelf-life. The shelf-life of a product can also be extended throughout storage and transportation period by maintaining high concentrations of antimicrobial ingredients.

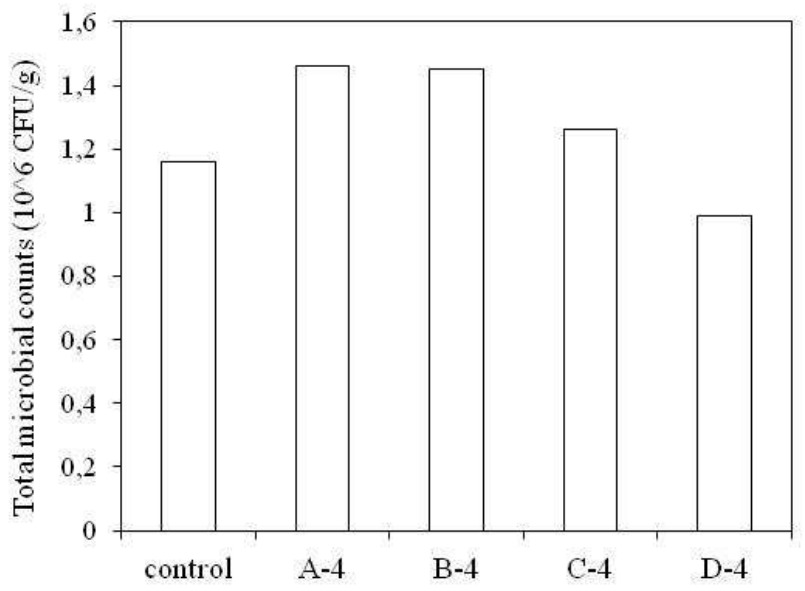

Fig. 5. Total microbial counts of meat (control: fresh meat; A-4: uncoated meat for four days of storage; B-4: coated meat without LGO for four days of storage; C-4: coated meat with $2 \%$ LGO for four days of storage; D-4: coated meat with $4 \%$ LGO for four days of storage)

\section{CONCLUSIONS}

The incorporation of LGO to edible film may have additional functions in direct food packaging. The experimental results showed that the edible films have antimicrobial behavior due to its surviving capability against Trichoderma sp and Penicillium sp. Nevertheless, further research is necessary to determine the composition or method of manufacture of cassava edible film incorporated with LGO which more appropriate to enhance the antimicrobial ability of edible film so that the inhibition zone can be formed for longer time. The antifugal properties of edible films can be applied for meat preservation. The incorporation of LGO to the film led to a reduction in bacterial content of meat as compared to samples coated without LGO. The results suggest that the films containing LGO may extend the shelf life of food.

\section{ACKNOWLEDGMENT}

The authors wish to acknowledge the Directorate Higher Education of the Republic of Indonesia for financial support 
under the project Hibah Kompetensi (Contract No. 169/UN11.2/LT/SP3/2014). One of the authors (Satriana) wishes to thank Universiti Kebangsaan Malaysia for providing Zamalah scholarship.

\section{REFERENCES}

[1] S. Burt, "Essential oils: Their antibacterial properties and potential applications in food - A review", Int. J. Food Microbiol. 94 (2004) 223-253

[2] J. Nguefack, V. Leth, P.H.A. Zollo and S.B. Mathur, "Evaluation of five essential oils from aromatic plants of Cameroon for controlling food spoilage and mycotoxin producing fungi. Int. J. Food Microbiol. 94 (2004) 329- 334

[3] J. Nguefack, J.B.L. Dongmo, C.D. Dakole, V. Leth, H.F. Vismer, J. Torp, E.F.N. Guemdjom, M. Mbeffo, O. Tamgue, D. Fotio, P.H.A. Zollo and A.E. Nkengfack, "Food preservative potential of essential oils and fractions from Cymbopogon citratus, Ocimum gratissimum and Thymus vulgaris against mycotoxigenic fungi”, Int. J. Food Microbiol. 131 (2009) 151-156

[4] J. Nguefack, O. Tamgue, J.B.L. Dongmo, C.D. Dakole, V. Leth, H.F. Vismer, P.H.A. Zollo and A.E. Nkengfack, "Synergistic action between fractions of essential oils from Cymbopogon citratus, Ocimum gratissimum and Thymus vulgaris against Penicillium expansum", Food Control 23 (2012) 377-383

[5] M. Viuda-Martos, Y. Ruiz-Navajas, J. Fernández-López, and J.A Pérez-Álvarez, "Antibacterial activity of different essential oils obtained from spices widely used in Mediterranean diet", Int J Food Sci. Tech. 43 (2008) 526-531

[6] J.M. Krochta, E.A. Baldwin and M.O. Nisperos-Carriedo, Edible coatings and films to improve food quality, Technomic Publishing Co. Inc. Lancester-Basel. USA, 1994

[7] S. Salmieri, and M. Lacroix, "Physicochemical properties of alginate/poly-caprolactone-based films containing essential oils", $J$. Agric. Food Chem. 54 (2006) 10205-10214

[8] Q. Wu and L. Zhang, "Structure and properties of casting films blended with starch and waterborne polyurethane", J. Appl. Polymer Sci. 79 (2001) 2006-2013

[9] A.C. Seydim, G. Sarikus, "Antimicrobial activity of whey protein based edible films incorporated with oregano, rosemary and garlic essential oils", Food Research Int. 39 (2006) 639-644
[10] J. Gutierrez, C. Barry-Ryan and P. Bourke, "The antimicrobial efficacy of plant essential oil combinations and interactions with food ingredients", Int. J. Food Microbiol. 124 (2008) 91-97

[11] J.H. Ahn, Y.P. Kim, E.M. Seo, Y.K. Choi and H.S. Kim, "Antioxidant effect of natural plant extracts on the microencapsulated high oleic sunflower oil", J. Food Eng. 84 (2008) 327-334

[12] R. Avila-Sosa, E. Palou, M.T.J. Munguía, G.V. Nevárez-Moorillón, A.R.N. Cruz, A. López-Malo, "Antifungal Activity by Vapor Contact of Essential Oils Added to Amaranth, Chitosan, or Starch Edible Films", Int. J. Food Microbiol. 153 (2012) 66-72

[13] W. Warkoyo, B. Rahardjo, D.W. Marseno and J.N.W. Karyadi, "Sifat fisik, mekanik dan barrier edible film berbasis pati umbi kimpul (Xanthosoma sagittifolium) yang diinkorporasi dengan kalium sorbat", Agritech, 34 (2014) 72-81

[14] C. Peroval, F. Debeaufort, D. Despre and A. Voilley, "Edible arabinoxylan-based films. 1. Effects of lipid type on water vapour permeability, film structure, and other physical characteristics", $J$. Agric. Food Chem. 50 (2002) 3977-3983

[15] H. Chen, "Functional properties and applications of edible films made of milk proteins", J. Dairy Sci. 78 (1995) 2563-2583

[16] G.O. Lim, S.A. Jang and K.B. Song, "Physical and antimicrobial properties of Gelidium corneum/nanoclay composite film cantaining grapefruit seed extract or thymol", J. Food Eng. 98 (2010) 415-420

[17] C. Pires, C. Ramos, B. Teixeira, I. Batista, M.L. Nunes and A Marques, "Hake proteins edible films incorporated with essential oils: Physical, mechanical, antioxidant and antibacterial properties", Food Hydrocolloids, 30 (2013) 224-231

[18] L. Atarés, C. De Jesús, P. Talens and A. Chiralt, "Characterization of SPI-based edible films incorporated with cinnamon or ginger essential oils", J Food Eng. 99 (2010) 384-391

[19] M. Somolinos, D. García, R. Pagán and B. Mackey, "Relationship between sublethal injury and microbial inactivation by the combination of high hydrostatic pressure and citral or tert-Butyl Hydroquinone", Appl. Environ. Microbiol. 74 (2008) 7570-7577

[20] M. Maizura,A. Fazilah, M.H. Norziah and A.A. Karim, "Antibacterial Activity of Modified Sago Starch-Alginate Based Edible Film Incorporated with Lemongrass (Cymbopogon citratus) Oil", Int Food Res J. 15 (2008) 233-236

[21] I. Liakos, L. Rizzello, D.J. Scurr, P.P. Pompa, I.S. Bayer and A. Athanassiou, "All-natural composite wound dressing films of essential oils encapsulated in sodium alginate with antimicrobial properties", Int J Pharma. 463 (2014) 137- 145 